\title{
LA PERSPECTIVA DE LA LIBERTAD REAL EN AMARTYA SEN ${ }^{1}$
}

José Luis Sepúlveda Férriz (UCSAL)

j-junior2008@hotmail.com

Resumo: O objetivo deste artigo é mostrar o conceito amplo de "liberdadereal", seguindo as análises e comentários de um autor notável, como Amartya Sen. Este conceito inspira a maioria das obras e artigos de nosso autor. Reflete-se, principalmente, em seu livro mais importante dos últimos anos: Desenvolvimento como liberdade. Analisamos os dois pontos de vista do conceito de "liberdade" neste artigo. Eles são o papel constitutivo e o instrumental. No primeiro papel se incluem três conceitos: a liberdade como um valor universal, Processos e Oportunidades, e a Liberdade como um compromisso social. No segundo papel compararemos liberdades instrumentais com a teoria de bens primários de Rawls.

Palavras-chave: Ética; economia; liberdade; bens primários; responsabilidade; racionalidade.

\section{INTRODUCCIÓN}

Recién estrenado el siglo XXI y el tercer milenio, en tiempos de globalización y de sociedades de información, no debemos olvidar que más de media humanidad vive al margen del desarrollo, de la libertad, de la justicia y, en definitiva, de una vida digna. Pensamos que nunca está de más realizar, otra vez, una reflexión desde la ética sobre el modelo de liberalismo económico que reina y que nos domina, con el objetivo de buscar los fundamentos filosóficos y los

\footnotetext{
${ }^{1}$ Recebido: 13-06-2013/Aprovado: 08-10-2013/Publicado on-line: 17-02-2014.

${ }^{2}$ Jose Luis Sepúlveda é Professor Substituto na UCSAL (Universidade Católica do Salvador), Salvador, BA, Brasil e Doutorando na Universidad Complutense de Madrid, UCM, Espanha.
} 
mecanismos políticos y económicos, que lo reorienten hacia una justicia social y económica, que reconcilie a toda la humanidad en un desarrollo auténticamente humano.

La reflexión ética ha estado vinculada a la economía desde su origen, tanto en occidente como en oriente, con Aristóteles o con Kautilya; y por supuesto, con el mismo Adam Smith, tal y como nos recuerda Amartya Sen (SEN 1987, P. 21). Sin embargo, por arte de una cierta mano invisible liberal y moderna, se fue secularizando -en sentido amplio- el pensamiento político en primer lugar, y el económico, en segundo. Desde finales del s. XX, Amartya Sen recoge el testigo de los orígenes clásicos de la economía, aquellos en los que el punto de vista moral enfocaba directamente a la actividad económica, el análisis y la reflexión con un desarrollo técnico y matemático propio de uno de los mejores economistas de nuestro tiempo (CASAS 1995, P. 11-31).

Su última obra, Development as freedom, ${ }^{3}$ es una constatación y denuncia desde la ética de la actual situación social, injusta y contradictoria, fruto de un modelo de desarrollo centrado en la riqueza, en la renta real y en tasas de crecimiento. Un modelo que no tiene en cuenta el desarollo humano en sentido amplio, entendido como expansión de las libertades fundamentales y de la democracia. El objetivo ahora es presentar un nuevo enfoque, que no pasa por sustituir ese liberalismo, ese reinado de la libertad, sino de transformarlo desde la ética y la reflexión sobre la justicia, que es fundamentalmente libertad, pero libertad real.

\footnotetext{
${ }^{3}$ SEN, A. Development as freedom, A. Knopf, Inc, 1999. Citaremos la traducción castellana Desarrollo y libertad, Planeta, Barcelona, 2000.
} 


\section{JUSTICIA SOCIAL Y ECONÓMICA: DE LA IGUALDAD A LA LIBERTAD}

A lo largo de la trayectoria de nuestro autor, podemos observar la evolución de un primer criterio de justicia basado en la igualdad, centrado en distintas formulaciones del bienestar, a un principio de libertad, pero entendida como libertad real. El mismo Van Parijs reconoce que es un concepto similar al que él mantiene en su modelo de liberalismo auténtico (VAN PARIJS 1996, P. 21-45).

Por ello, podemos identificar los primeros planteamientos de Sen dentro de la economía del bienestar, y en primer lugar, dentro de la escuela de la elección social, donde se formó como economista con Kenneth Arrow ${ }^{4}$. Su principal preocupación era presentar una alternativa viable a la economía basada en una concepción utilitarista, que fundamentaba los modelos económicos neoclásicos y que, precisamente, están en la base teórica de las desigualdades injustas denunciadas por Sen. Una labor similar nos ofreció John Rawls con su Teoría de la Justicia, en 1971. De hecho, es constante el diálogo y el debate entre ambos autores a lo largo de su trayectoria.

Posteriormente, a lo largo de los años noventa, con la publicación de algunos de sus principales artículos como Justice: means versus freedoms o Markets and freedoms ${ }^{5}$ podemos poner de manifiesto que se produce un cambio de enfoque hacia planteamientos basados en la libertad real. Propuesta claramente definida en Desarrollo y libertad, donde defiende

\footnotetext{
${ }^{4}$ Dentro de la Escuela de la Elección Social, la obra más significativa de Sen es Elección colectiva y bienestar social, Alianza, Madrid, 1976.

${ }^{5}$ SEN, A. "Justicia: medios contra fines", Nueva economía del Bienestar. A. Sen, "Mercados y libertades. Logros y limitaciones del mecanismo de mercado en el fomento de las libertades individuales” en Bienestar, justicia y mercado, Paidós, Barcelona, 1997.
} 
una teoría de la justicia económica y del desarrollo humano, analizada claramente desde una perspectiva de la libertad real y no sólo del bienestar. En esta obra, nos presenta un planteamiento de ética y justicia económica que entiende el desarrollo como desarrollo humano, es decir, no sólo como aumento del PIB o de la renta disponible, sino como aumento y expansión de las libertades fundamentales, donde las condiciones materiales de la libertad deben estar garantizadas, y donde la libertad se constituye como el principio legislador y regidor de una sociedad justa. Incluso, yendo aún más lejos, este principio de la libertad se puede considerar una aplicación de la eleuteronomía kantiana al orden económico, tal y como propone Jesús Conill ${ }^{6}$

Dentro de la perspectiva de la libertad, Amartya Sen distingue algo muy importante: la libertad como fin en sí mismo y las libertades como medios o instrumentos. De ello tenemos ya muestras en Justicia, medios contra fines, en el debate entablado con Rawls respecto al papel de los bienes primarios como fines o medios para la libertad (PEDRAJAS 2001, P. 53-93); y sobre todo, en Desarrollo y libertad donde profundiza en la distinción entre fines y medios, tema en el que, además, basó su intervención en el Symposium on Global Finance and Development organizado por el Banco Mundial y celebrado en Tokio en marzo de 1999.

En este predominio de la libertad como principio de

\footnotetext{
${ }^{6}$ La eleuteronomía consiste en erigir el principio de la libertad como fundamento de la legislación interna de la razón práctica. Esta conclusión es fruto de la aplicación del método trascendental al orden de la razón práctica, como establece el propio Kant. Cf. CONILL, J. "Mercado y Justicia: un reto para la ética económica contemporánea" en Retos pendientes en ética y política, Suplemento 5 de Contrastes, Málaga, 2000, p. 247-257. Cf. CONILL, J., "Bases éticas del enfoque de las capacidades de Amartya Sen" en Sistema 171, noviembre 2002, p. 58-60. Cf. CONILL, J., El enigma del animal fantástico, Tecnos, Madrid, 1991. Cf. KANT, E., La metafísica de las costumbres, Tecnos, Madrid, 1999.
} 
justicia vamos a centrar este artículo, distinguiendo las dos vertientes: la libertad como fin en sí mismo y como medio para el desarrollo.

\section{LA LIBERTAD COMO FIN ÚLTIMO}

"Todo conocimiento y toda elección tienden a algún bien... la felicidad" nos dijo Aristóteles, para señalar a continuación que la misma no consiste ni en el placer, ni en la riqueza, ni en los honores, en una de las citas a las que con más frecuencia recurre Sen ${ }^{\text {? }}$.

Nos encontramos a lo largo de la historia con diferentes propuestas sobre el fin de las acciones humanas. Muchas de ellas insisten en la libertad como medio para conseguir ese preciado fin, sea el que sea. Pero la libertad no es solamente un medio, es algo más. También puede y debe reflexionarse sobre ella como un fin, el fin al que se dirige la acción humana: ser libres, llevar una vida de libertad, que será (o podrá ser) una vida dichosa, o por lo menos, justa. Enmarcamos esta libertad dentro de una teoría de la justicia en sociedad, donde la justicia económica es un elemento básico. Tiene un sentido matizado, es una libertad que es condición de posibilidad de la justicia y es el elemento definidor de la justicia (CONILL2000, P. 256).. Pero es una libertad realizable, real, pragmática, posible, histórica, material y política. En definitiva, una libertad que es fundamento de un nuevo liberalismo, más social, aplicado a la economía y, por tanto, a la sociedad.

Sobre el papel relevante de la libertad en las relaciones políticas y económicas han escrito numerosos pensadores,

\footnotetext{
${ }^{7}$ (ARISTÓTELES 1999, Libro 1,4, P. 3). Cf. (SEN 2000b, P. 30).
} 
filósofos, políticos, economistas, etc., a lo largo de la historia de la ética, y Amartya Sen es uno de ellos, pero sus fuentes vienen desde Aristóteles, Kant, Adam Smith y Marx hasta Arrow, Rawls o Dworkin.

A la hora de profundizar en este papel constitutivo de la libertad, vamos a estructurar la argumentación de Sen en tres puntos: a) la libertad como valor universal, b) el concepto de libertad: oportunidades y procesos y c) la libertad como compromiso social.

\section{a) La libertad como valor universal}

La libertad en su papel constitutivo, como fin en sí mismo, está estudiada, principalmente, en Desarrollo y libertad. Como hemos comentado, la principal novedad de esta obra es el enfoque general de la perspectiva de la libertad, de tal modo que tanto la libertad (como la democracia) se conciben como valores intrínsecos al desarrollo y, por tanto, a la justicia económica y social. Sin expansión de la libertad (y de las libertades) el desarrollo no es humanamente completo. Por eso, para Sen, las principales deficiencias de los modelos "tradicionales" de desarrollo económico es concebirlos como ausencia de renta, en lugar de una ausencia de libertades. Por ello afirma: "No es sensato concebir el crecimiento económico como un fin en sí mismo [...] la expansión de las libertades nos permite ser personas sociales más plenas, que ejercen su propia voluntad e interactúan con -e influyen en- el mundo en el que viven" (SEN 2000b, P. 3).

Este concepto de desarrollo está fundamentado sobre la base de la concepción de la libertad como valor universal. A este tema dedica Sen el capítulo décimo de su última obra, donde plantea en términos muy sugerentes el valor univer- 
sal de la libertad. El origen asiático y su amplia formación en occidente colocan a nuestro autor en un lugar privilegiado para debatir sobre esta materia. El conflicto se encuentra principalmente entre valores asiáticos (donde la autoridad y la lealtad están fuertemente arraigadas) frente a los valores occidentales de la libertad, tolerancia, pluralismo, etc. Para nuestro autor, la libertad queda excluida de este debate, puesto que un estudio crítico sobre los valores asiáticos no concluye en una negación de la universalidad de la libertad. El argumento a favor de las libertades se apoya en tres razones: su importancia intrinseca, su trascendental contribución a dar incentivos políticos para proporcionar seguridad económica y, en tercer lugar, su papel constructivo en la génesis de valores y prioridades. Estas razones, para Sen, no son distintas en Asia (IBID P. 298); y en caso de que alguien lo juzgara así, piensa nuestro autor que sería desde un punto de vista occidental y sesgado.

Para otras tradiciones éticas este es un punto clave de discusión y debate. Aunque Sen no dialoga directamente con los comunitaristas, desde este punto de vista se puede considerar que la libertad como valor universal puede ser perjudicial, al cuestionar el mantenimiento de las tradiciones culturales más arraigadas. La libertad puede ser un factor decisivo de bloqueo y de cambio cultural, por ello, no afirmarán con la rotundidad que hace Sen que la libertad es un valor intrínseco. El desarrollo como libertad y la libertad en el desarrollo, puede poner en serio peligro la herencia cultural.

Como señala Kymlicka, el comunitarismo discute la concepción de la persona propia del liberalismo sintetizada en la idea de Rawls de que cualquier fin o proyecto vital puede ser siempre susceptible de revisión desde un "Yo 
desvinculado". Esta afirmación de origen kantiano implica que más allá de su pertenencia a cualquier grupo, categoría, entidad o comunidad (ya sea de tipo religioso, económico, social o sexual) los individuos tienen (y es valioso que tengan) la capacidad de cuestionar tales relaciones hasta el punto, incluso, de separarse de ellas si es que así lo prefieren. Para el comunitarismo, en cambio, nuestra identidad como personas, al menos en parte, se encuentra profundamente marcada por nuestra pertenencia a ciertos grupos: nacemos insertos en ciertas comunidades y prácticas sin las cuales dejaríamos de ser quienes somos. Dichos vínculos aparecen así como vínculos valiosos, en cuanto esenciales en la definición de nuestra identidad ${ }^{8}$. Para los comunitaristas, los liberales presentan una idea vacía de libertad; frente a ella, defienden una libertad situada, capaz de tomar en cuenta nuestro "formar parte" de ciertas prácticas y valores compartidos".

En este sentido, como buen liberal, Amartya Sen afirma: "En la perspectiva basada en la libertad, ni los guardianes nacionales, ni los ayatollahs, ni los dirigentes políticos, ni los expertos culturales, pueden impedir a nadie participar en la elección de las tradiciones que deben mantenerse. La indicación de que existe un conflicto real entre la preservación de la tradición y las ventajas de la modernidad exige una resolución en la que participe todo el mundo, no el rechazo unilateral de la modernidad a favor de la tradición por parte de los dirigentes políticos, de las autoridades reli-

\footnotetext{
${ }^{8}$ La identidad de cada uno, según Taylor, se define en buena medida a partir del conocimiento de dónde se halla uno ubicado, cuáles son sus relaciones y compromisos: con quiénes y con qué proyectos se siente identificado. Cf. (TAYLOR 1996).

9 (KYMLICKA 1995, P. 228-238). Cf. (GARGARELlA 1999, P. 127). Cf. (CONILL 1998, P. 213-258).
} 
giosas o de los admiradores antropológicos de los legados del pasado" (SEN 2000b, P. 298).

Pero también reivindica su protección frente a la globalización de los valores occidentales. La diversidad de culturas, para nuestro autor, también es un valor en sí mismo. "El reconocimiento de la diversidad dentro de las diferentes culturas es muy importante en el mundo moderno. El constante bombardeo con generalizaciones excesivamente simples sobre la civilización occidental, los valores africanos, etc., tiende a socavar algo nuestra comprensión de la presencia de la diversidad"10. La libertad es real, y siguiendo la tradición hermenéutica se podría definir como una libertad situada; pero que es un valor universal, eso no se pone en cuestión ${ }^{11}$.

Por último, la justificación de la libertad como fin, su valoración como objetivo último del desarrollo y de la justicia, se estructura en torno a dos tipos de razones: razón de la evaluación y de la eficacia. Por la primera, quiere decir que la libertad es el criterio en función del cual se ha de evaluar el éxito de la sociedad desde el punto de vista de la justicia; mientras que por la segunda, hemos de considerar esenciales las libertades fundamentales, porque la libertad es un importante determinante de la iniciativa individual y de la eficacia social. "El aumento de la libertad mejora la capacidad de los individuos para ayudarse a sí mismos, así como para influir en el mundo, y estos temas son fundamentales

\footnotetext{
${ }^{10}$ Ibidem.

${ }^{11}$ Una aportación que nos parece muy adecuada y con la que Sen no dialoga en sus escritos, por lo menos hasta ahora, es la proveniente del liberalismo dialógico-hermenéutico, siguiendo la formulación del profesor Agustín Domingo. Desde esta variante, se reconstruyen los principios filosóficos del liberalismo no sólo desde la antropología, sino desde la sociedad de la que han emergido, del Lebenswelt, reconstruyendo a la vez el proyecto ético de la modernidad. Esta corriente estaría formada por autores como Ch. Taylor, A. Cortina o N. Bellah. Cf. (DOMINGO 1998, P. 322).
} 
para el proceso de desarrollo" (SEN 2000b, P. 34). Esta razón está directamente relacionada con la faceta de "agencia" de la persona, con la capacidad de iniciativa del individuo ${ }^{12}$.

b) Concepto de libertad: oportunidades y procesos

La libertad fundamental y universal, la que es constitutiva del desarrollo, tiene dos vertientes que Sen analiza en profundidad desde escritos anteriores: la libertad como procesos y la libertad como oportunidades, y la expansión de ambas constituye intrínsecamente el desarrollo. Aprovechando la sentencia de Aristóteles, con la que iniciamos este punto, marca las diferencias entre las teorías del desarrollo como expansión de las libertades de aquellas que lo conciben, únicamente, como maximización de la riqueza o del PNB. Aunque reconoce la relación entre ambas, se centra en las diferencias, que quedan justificadas por ese doble aspecto de la libertad: procesos y oportunidades. "La concepción de la libertad que adoptamos aquí entraña tanto los procesos que hacen posible la libertad de acción y de decisión como las oportunidades reales que tienen los individuos, dadas sus circunstancias personales y sociales" ${ }^{13}$. La libertad se refiere tanto a los procesos de toma de decisiones como a las oportunidades para lograr resultados valorados (SEN 2000b, P. 348).

En Desarrollo y libertad encontramos este doble concepto de libertad, pero aparece ya en artículos anteriores. En las conferencias Arrow, Freedom, Rationality and Social Choice (1991) y en Mercados y libertades (1993) presenta este doble

\footnotetext{
${ }^{12}$ La concepción de la persona moral de Sen se basa en dos facetas: agencia y bienestar. Cf. (SEN 1987, P. 58-76). (SEN 1997, P. 63) y (SEN 2000b, P. 35-36).

${ }^{13}$ SEN, A. Freedom, Rationality and Social Choice: Arrow lectures and other essays, Clarendon Press, Oxford, 2000, citado en A. Sen, Desarrollo y libertad, p. 33.
} 
planteamiento de la libertad, aprovechando la distinción entre "eficiencia" y "eficacia". Mercados y libertades constituye una reflexión sobre la libertad como concepto para legitimar el mercado: "tenemos que explorar las distintas facetas de la libertad individual y sus relaciones -si las tuvieran- con la naturaleza de los equilibrios de los mercados competitivos (SEN 1997, P. 124)".

Podemos estructurar la libertad en dos facetas principales.

b.1) oportunidades sustantivas.

b.2) consideraciones de procesos, donde a su vez se distinguen:

- la autonomía decisional y

- la inmunidad frente a las intrusiones.

Según esta clasificación, podemos observar cierto reflejo de los dos conceptos de libertad de Berlin, la libertad negativa se correspondería a la inmunidad frente a terceros, la cual comparten principalmente teóricos de la política y de la economía como Nozick, Hayek, Milton Friedman, Frank Knight y, en general, la escuela de Chicago.

Pero por otra parte, la libertad positiva de Berlin no encuentra su formulación totalmente equivalente en la de Sen, pues éste afirma que: "Berlin piensa la libertad positiva en términos más reducidos, en particular en términos de superar los obstáculos que provienen de dentro de la persona, no los de fuera" (IBID P. 131). El propio Sen, Dworkin o Joseph Raz mantienen un concepto de libertad positiva 
más amplia ${ }^{14}$. Para nuestro autor, la libertad positiva se ampliaría con la autonomía decisional y las oportunidades sustantivas. A continuación desarrollaremos más estos conceptos.

\section{b.1) Libertad como oportunidades sustantivas}

La libertad como oportunidad se refiere a "la oportunidad de lograr nuestros objetivos: las cosas que tenemos razones para valorar. La faceta de oportunidad se refiere, pues, a la capacidad real para conseguir cosas" (SEN 1997, P. 128), pero es posible y necesario extenderla teniendo en cuenta además el espectro de oportunidades ofrecidas.

Desde este punto de vista, en el análisis del desarrollo y la justicia social como libertad, es necesario ir más allá del punto de vista estrictamente económico y tener en cuenta las cuestiones como la oportunidad real de vivir muchos años, escapar de la morbilidad evitable, o la oportunidad de tener un empleo que merezca la pena. Son variables que apuntan a oportunidades que los individuos tienen razones para valorar y que no están relacionadas estrictamente con la prosperidad económica. No solamente son importantes los niveles de renta real que dan oportunidad de comprar bienes y servicios y disfrutar del nivel de vida que va unido a esas compras, la libertad real nos exige por justicia otro tipo de oportunidades.

Desde este análisis se pueden establecer dos relaciones. Por un lado, Sen retoma la distinción de Hayek al hablar de la importancia intrinseca y la importancia derivada de las

\footnotetext{
${ }^{14} \mathrm{Raz}$ mantiene que puede ser necesario el apoyo estatal para asegurar la suficiente diversidad de opciones para aquellos que aún no se hayan formado sus objetivos vitales. Cf. (RAZ 1986). Cf. (DWORKIN 1995). (DWORKIN 1993).
} 
oportunidades, de tal modo que, en un ejemplo al que suele recurrir con frecuencia, no es lo mismo elegir ayunar y morir por ello, que morir víctima de una hambruna, sin opción ${ }^{15}$. Por otro lado y dentro de la teoría económica, la libertad como oportunidad es la libertad de la teoría del consumidor del modelo de Samuelson, al considerar la evaluación de los conjuntos presupuestarios, en una concepción simplista de la libertad en ausencia de incertidumbre ${ }^{16}$.

\section{b.2) Libertad de procesos}

Desde el punto de vista de la libertad como procesos o procedimientos, podemos afirmar que en el análisis del desarrollo se deben incluir ciertos procesos como la participación en las decisiones políticas y debates, que no son meros medios para el crecimiento económico, sino que además son partes constitutivas de los fines mismos del desarrollo. Por ello es insuficiente analizar el desarrollo desde el punto de vista de aumento de la riqueza, desde una perspectiva únicamente económica.

En la consideración de los procesos cabría distinguir: la autonomía decisional y la inmunidad frente a terceros. La primera hace referencia a la capacidad de decidir por uno mismo, un proceso de elección autónoma, el hecho de tener en nuestras manos el control (aumenten o no las opor-

\footnotetext{
${ }^{15}$ (HAYEK 1960, P. 31). Cf. (SEN 2000b, P. 349).

${ }^{16}$ Concretamente, las oportunidades reales que una persona tiene para llevar (sujeta a fuertes restricciones) la vida que elegiría, son esenciales en la evaluación social. Para valorar este grado de oportunidad real, hemos de vincularlo al conjunto de consecuciones alternativas entre las que puede elegir. Por tanto, dichas consecuciones son la clave del razonamiento. En teoría económica, esas consecuciones están expresadas como preferencias, en relación a la teoría de la preferencia revelada de Samuelson. Sen se muestra crítico y destaca la ambigüedad de la conexión oportunidades-preferencias. Crítica reafirmada sobre la base del rango de elección, ausente en la preferencia revelada. Cf. SAMUELSON, P. "A note on the pure theory of consumer's behaviour", Economica 5, 1938. (SEN 1997, P. 136) y (NUSSBAUM 1998, P. 60).
} 
tunidades reales de conseguir nuestros objetivos). "la autonomía decisional se refiere al papel operativo que una persona tiene en el proceso de elección y lo esencial en ello es que uno mismo tome las decisiones, por ejemplo, el que las elecciones se hagan por la persona misma -no por otros individuos o instituciones (ni en su nombre). Esto exige la identificación del dominio propio de las decisiones autónomas" (SEN 1997, P. 130). Este enfoque procedimental se puede contrastar con la Escuela de la Elección Pública, Public Choice, en la versión de James Buchanan, quien propone un modelo constitucional para fundamentar normativamente y procedimentalmente la organización y acción social ${ }^{17}$.

Por otra parte, el significado de inmunidad frente a terceros, concretado en la interpretación del término "interferencia”, ha sido uno de los aspectos más debatidos junto con la filosofía libertaria. En este sentido, para autores como Nozick y Hayek, el único papel que debe tener el Estado es asegurar que no hay interferencias ni intromisiones en los derechos personales (principalmente el de propiedad) de cada individuo ni en la libertad personal como espacio vital (SEN 2000b, P. 34). Es lo que propiamente se ha denominado "libertad negativa".

\section{c) La libertad como compromiso social}

Por último, es necesario tener en cuenta que para resolver los problemas a los que nos enfrentamos, hemos de concebir la libertad individual como un compromiso social, el último capítulo de Desarrollo y libertad está dedicado a esta noción. Para Amartya Sen, es necesario percatarse de nues-

${ }^{17}$ Cf. (BRENNAM 1987). Cf. (CONILL1993, P. 32) y (CONILL 2001, P. 353-372). 
tra humanidad compartida para tomar decisiones. Nuestro sentido de la responsabilidad no tiene por qué referirse sólo a las aflicciones que puede causar nuestra propia conducta (aunque eso también puede ser muy importante) sino también, en términos más generales, a las miserias que observamos a nuestro alrededor y está a nuestro alcance remediar (IBID P. 339).

Esta responsabilidad compartida no debe suponer una pérdida de elementos importantes como la motivación, la participación, la iniciativa, el esfuerzo individual e incluso la dignidad humana. Amartya Sen evita caer en el diseño de un estado paternalista.

Debe pensarse el papel del estado pero también de otras organizaciones sociales y políticas, de los movimientos ciudadanos, de las organizaciones solidarias, de los medios de comunicación, etc., todos juegan un papel en el desarrollo pleno de la libertad y la justicia. Para todo ello, el papel de la democracia, del debate público, las organizaciones sociales, etc., son decisivos. A diferencia del liberalismo clásico y de los neoliberalismos libertarios, el liberalismo de Amartya Sen se sitúa en la misma línea que autores como Rawls, Scanlon, Dworkin, Van Parijs o Cortina, la línea de un liberalismo social, solidario y humano.

\section{LA LIBERTAD COMO MEDIO, INSTRUMENTO PARA EL DESARROLLO}

La libertad como fin, la libertad como objetivo último del desarrollo económico y político, como justicia social, pasa por garantizar unas libertades-medios. Hace falta completar el análisis anterior con un análisis intermedio de la libertad, que la entiende en su papel instrumental. La libertad como 
medio está compuesta por cinco libertades:

- libertades políticas

- servicios económicos

- oportunidades sociales

- garantías de transparencia

- seguridad protectora

El "argumento instrumental" consiste en que las libertades y derechos también pueden contribuir de manera eficaz al progreso económico, es un análisis referido a la forma en que los derechos y las oportunidades contribuyen al desarrollo humano, entendido como expansión de las libertades. La eficacia de este argumento viene dada por las interconexiones que se establecen entre los distintos elementos intermedios, de tal manera que un tipo de libertad puede contribuir extraordinariamente a aumentar otros, favoreciendo, a largo plazo, la libertad como fin constitutivo, como desarrollo humano (SEN 2000b, P. 56-57).

El estudio de Sen, en el capítulo 2 de Desarrollo y libertad, se centra también en estas distintas conexiones e interrelaciones de las libertades intermedias entre ellas y con el objetivo último, el desarrollo. Es un análisis muy similar al de los bienes primarios de Rawls, de hecho, nos lo recuerda en numerosas ocasiones y así lo hemos intentado mostrar.

Es el propio Sen el que califica la teoría de los bienes primarios como una doctrina de medios para la libertad (SEN 1995, P. 463). En este sentido, nuestra postura será crítica con el propio Sen, ya que trataremos de justificar que el análisis de algún bien primario de Rawls (concretamente, el quinto, el autorrespeto) nos parece más completo y 
con un contenido que no encontramos en ninguna de las libertades-instrumentales de Sen.

Sin embargo, también conviene tener en cuenta algunas ventajas que presenta Sen respecto al esquema rawlsiano, al incluir sistemas de educación y sanidad entre las libertades fundamentales a nivel intermedio. Para nuestro autor, siempre hay que ir más allá de los bienes primarios. En la introducción a Choice, Welfare and Measurement, incluso adopta el punto de vista de lo que las personas obtienen de los bienes primarios, que dependerá de una variedad de factores y no sólo del tamaño de la propiedad personal de bienes y servicios, en una clara alusión a lo que Gerald Cohen planteará como vía media ${ }^{18}$. En Dworkin, la articulación de una teoría de la justicia, basada en medios como son los "recursos", es mucho más complicada e implica el uso de una "subasta", esquemas de seguro, mercados libres e impuestos, en este artículo sólo haremos breves referencias a la misma, en cuanto al contraste que supone con la teoría de Sen.

\section{a) Libertades políticas}

En sentido amplio se refieren a la libertad de conciencia (política), de expresión y al pluralismo político, y los dere-

\footnotetext{
${ }^{18}$ La teoría de la vía media sería una revisión del enfoque de las capacidades realizada desde un liberalismo igualitarista. En concreto, Cohen critica la ambigüedad del enfoque de las capacidades de Sen y propone la vía media como aquella que tiene en cuenta lo que los bienes pueden hacer por las personas, en lugar de centrarse únicamente en lo que las personas pueden hacer con los bienes o en la utilidad extraída de los mismos. La respuesta de Sen está en la propia noción de capacidad. Para Sen, la palabra griega crucial es dynamin, puede traducirse como "capacidad para existir o actuar" y es de suponer que "existir" no debe ser necesariamente el resultado de algún vigoroso ejercicio de capacidad. En definitiva, será un equivalente de las capacidades entendidas como libertad. Pero pensamos que Cohen no llega a comprender este dato en su totalidad. Cf. COHEN, G. "Igualdad, ¿de qué? Sobre el bienestar, los bienes y las capacidades" en NUSSBAUM, M. y SEN, A. La calidad de vida, FCE, Madrid, 1998, P. 27-53.
} 
chos de voto y de oposición política de las democracias. Concretamente, hace especial hincapié en la oportunidad de decidir quién gobierna, en los mecanismos de legitimación del poder político, en la libertad de oposición política, de investigar y criticar a las autoridades, en la libertad de prensa sin censura, en la posibilidad de dialogar, disentir y criticar en el terreno político, así como en el derecho de participación en la selección del poder legislativo y del poder ejecutivo (SEN 2000b, P. 57).

Rawls nos ofreció, anteriormente, un análisis similar en el artículo "Las libertades básicas y su primacía" (RAWLS 1990, P. 33-122), donde haciéndose eco de esa tradición democrática de las sociedades occidentales, las diversas constituciones y los derechos humanos llega a las mismas conclusiones (a la misma lista de libertades básicas o políticas que forman el primer bien primario), aunque por otra vía, la de la "posición original". La conclusión es el establecimiento del derecho a las libertades básicas para todas las personas, por encima de razones de bien público y de los valores perfeccionistas, en clara alusión al utilitarismo y, añade, a la economía del bienestar. Estas libertades básicas son, fundamentalmente, las mismas libertades políticas de las que nos habla Sen: libertad de pensamiento y de conciencia, libertades políticas de asociación, libertades especificadas en la libertad física y en la integridad de la persona y derechos y libertades que incluye el principio de legalidad (IBID P. 54-122).

De esta lista de libertades sólo se enuncia su forma y su contenido general en la "posición original" y se establecen las razones de su prioridad, pero deberá ser posteriormente especificada en las etapas constitucionales, legislativa y judicial dentro de los "márgenes centrales de aplicación" (IBID 
P. 40), dentro de los cuales las libertades pueden hacerse compatibles entre sí.

Otros debates que surgen al hilo de la definición de las libertades básicas son los relativos a la prioridad de una de ellas a la hora de hacer frente a un conflicto de libertades. Para Rawls, siguiendo la formulación de Constant, las libertades de los modernos no se deben valorar por encima de la de los antiguos, las libertades políticas no son menores que la libertad de pensamiento y conciencia. Esto sería otorgar un papel fundamentalmente instrumental para la consecución de las demás libertades. Por ello, determinadas libertades políticas deben contar entre las libertades básicas y deben estar protegidas mediante la primacía de la libertad, y justificará a continuación esta primacía de las libertades políticas, como medios institucionales esenciales para garantizar todas las otras libertades en un estado moderno (RAWLS 1996, P. 336).

Por otra parte, en Dworkin se identifican estas libertades fundamentales con los derechos básicos de primera generación que deben ser un elemento principal del compromiso serio de los gobiernos para disminuir las desigualdades injustas, en un modelo de liberalismo más igualitario que el de Rawls, y una justicia distributiva más redistributiva. En cualquier caso, Sen tampoco comparte el modelo de Dworkin, precisamente por poner todo el peso específico en estos medios (recursos) para la justicia, en lugar de plantear la justicia como libertad real y ésta, como valor universal ${ }^{19}$.

b) Servicios económicos

\footnotetext{
${ }^{19}$ (DWORKIN 1995). (DWORKIN 1993)
} 
Son los recursos, que no incluyen sólo rentas y riqueza, como el cuarto bien primario de Rawls. Al igual que hemos expuesto en el punto anterior las libertades políticas, ahora nos referimos a libertades y derechos económicos. Entre ellos se incluyen la libertad de realizar intercambios, producir o consumir recursos. Del mismo modo, se incluye la existencia y el acceso a recursos financieros (la obtención de créditos, por ejemplo) por parte de los agentes económicos, desde una gran empresa hasta un consumidor y, en general, todos los derechos y libertades que se dan en el contexto de una mayor o menor libertad de funcionamiento de los mercados (condiciones de intercambio y precios relativos). Todo ello puede influir de manera decisiva en el proceso económico que eleva la renta y la riqueza de un país, que a su vez, se traduce en el aumento de libertades y derechos económicos de la población (SEN 2000b, P. 58).

El cuarto bien primario de Rawls hacía referencia a "ingresos y riqueza”, concebidos en términos amplios como medios de uso universal con valor de cambio. Los ingresos y riqueza eran, de este modo, necesarios para alcanzar directamente o indirectamente una amplia gama de fines, sean cuales fueren (RAWLS 1996, P. 345)..

No encontramos una formulación tan exhaustiva de derechos y libertades económicas, aunque en el segundo bien primario se incluye "la libertad de movimiento y de empleo concebido en el marco de diversas oportunidades", pero no hace referencia a derechos económicos, sino al marco general de las oportunidades entendidas como "esencias constitucionales" (definidas por las libertades básicas respecto de los principios que regulan las desigualdades económicas y sociales) en el capítulo dedicado a la "razón pública". La igualdad de oportunidades es algo más 
que una "esencia constitucional" (es más exigente, es un principio de justicia) mientras que algún principio de oportunidades (como este bien primario) sí es una esencia de este tipo (IBID P. 263-266).

Para Rawls, hablar de derechos y libertades económicas supondría traspasar los límites de una justicia estrictamente política. En cambio para Dworkin, los "recursos" son la variable verdaderamente importante. En Dworkin podemos observar muchos puntos en común con Rawls, pero también algunas diferencias importantes que se relacionan estrechamente con la crítica de Sen al mismo Rawls. El punto de desencuentro fundamental será la diversidad humana, resultado de esa especie de "lotería natural" por la que unos individuos están en situaciones de partida diferentes, con diferentes talentos, habilidades, incluso con diferentes condiciones de salud, medio ambiente, etc. La diversidad humana es una noción fundamental en Sen, y tema de confrontaciones en el liberalismo en general ${ }^{20}$.

Nuestro autor llega a identificar cinco fuentes de diversidad y así lo expone en Desarrollo y libertad. Nuestras diferencias son de origen natural o de origen social. Entre las primeras podemos incluir la heterogeneidad personal o simplemente la diversidad relacionada con el medio ambiente. Y entre los factores sociales que nos hacen radicalmente diferentes podemos encontrar el clima social, las perspectivas relacionales e incluso la distribución dentro de la familia. Volviendo a la argumentación de Dworkin, los recursos son de dos tipos fundamentalmente: los recursos personales o internos (que incluyen, habilidades físicas,

\footnotetext{
${ }^{20}$ Respecto a la diversidad humana la exposición más detallada de A. Sen se encuentra en Desarrollo y libertad, P. 94-96.
} 
mentales, la salud, etc.) y los recursos impersonales o externos (tierra, maquinarias, etc.).

En la subasta de la sociedad, sólo se ponen a remate los recursos impersonales, que podemos identificar con los recursos económicos de Sen, pero también con la categoría siguiente. La clave está en igualar en recursos externos, superando el test de la envidia, y articular un sistema de seguros y de redistribución e impuestos, que amortigüe la desigualdad provocada por la distinta dotación de recursos internos, que no entran a subasta, como es obvio ${ }^{21}$

\section{c) Las oportunidades sociales}

Al igual que hemos hablado de recursos económicos, en sentido amplio, ahora nos referimos a recursos sociales, en el mismo sentido. Son principalmente los sistemas públicos de educación y sanidad que tiene la sociedad. Son los servicios públicos más importantes, no sólo para llevar una vida sana, sino por el aumento de la libertad de participar más eficazmente en actividades económicas y políticas que conlleva. Combatir el analfabetismo aumenta las libertades fundamentales de los individuos, supone aumentar las oportunidades de participación política, o simplemente tener la posibilidad de leer la prensa o comunicarse por escrito.

En relación a Dworkin, como dijimos anteriormente, tan importantes son los derechos de primera generación (libertades fundamentales) como los de segunda generación, donde se encuentran el derecho a la educación, la cultura y la salud. Una teoría de la justicia que se tome los derechos en

\footnotetext{
${ }^{21}$ Cf. (DWORKIN 1995). Cf. (DWORKIN, 1993). Cf. (KYMLICKA 1995, P. 91-101). Cf. (DOMINGO 1998). Cf. (VAN PARIJS 1998, P. 147-149).
} 
serio debe articular un sistema de gobierno y de Estado, que siendo imparcial (que no inactivo), garantice el pleno desarrollo de estos derechos a todos los ciudadanos. Es un compromiso por el igualitarismo más radical que en Rawls, para quien no se deben exceder los límites marcados por los bienes primarios como elemento de la justicia, que es estrictamente política.

\section{d) Las garantías de transparencia}

Se refiere a la confianza como una libertad fundamental que garantiza el limpio funcionamiento de todos los demás mecanismos sociales, de las actividades políticas y económicas. La confianza es decisiva en las relaciones sociales, los individuos se interrelacionan basándose en lo que suponen que se les ofrece y en lo que pueden esperar obtener. En este sentido, la sociedad funciona presuponiendo la existencia de un mínimo grado de confianza. Las garantías de transparencia se refieren a la necesidad de franqueza que pueden esperar los individuos: la libertad para interrelacionarse con la garantía de divulgación de información y de claridad. Esas garantías desempeñan un claro papel instrumental en la prevención de la corrupción, de la irresponsabilidad financiera y de los tratos poco limpios (SEN 2000B, P. 59)

\section{e) La seguridad protectora}

Por último, con independencia de lo bien que funcione un sistema económico, algunas personas pueden ser muy vulnerables y verse sumidas, de hecho, en grandes privaciones como consecuencia de cambios materiales que afectan negativamente a su vida. La seguridad protectora es necesaria para proporcionar una red de protección social que impida 
que la población afectada caiga en la mayor de las miserias, y en algunos casos, en la inanición y la muerte. Comprende mecanismos institucionales fijos como las prestaciones por desempleo y las ayudas económicas fijadas por la ley para los indigentes, así como mecanismos ad hoc como ayudas para aliviar las hambrunas o empleo público de emergencia para proporcionar unos ingresos a los pobres ${ }^{22}$.

En el liberalismo igualitarista de Dworkin, un concepto similar es el del seguro, a través de su contratación, los individuos pueden afrontar aquellos problemas que no pudieron ser resueltos a partir de la adquisición de recursos externos en la mencionada subasta, donde no se incluían los recursos personales o internos. Van Parijs lo califica como "seguridad detrás de un velo de ignorancia" y recoge las observaciones de Roemer a Dworkin a propósito de este esquema de seguros (VAN PARIJS 1996, P. 90 y 112).

Los problemas teóricos en base a la contratación del seguro, las tasas impositivas, la redistribución, etc., son parte del contenido de la justicia de Dworkin, que exceden las pretensiones de este artículo.

Por su parte, en la justicia como equidad de Rawls, una noción similar, con reservas, a estas dos últimas libertades intermedias, puede ser el quinto -y principal- bien primario: las bases sociales del autorrespeto. A nuestro juicio, es mucho más rico el bien primario de Rawls que las garantías de transparencia o la seguridad protectora.

La idea que subyace a las mismas puede asimilarse, dado que las "bases sociales" del autorrespeto deberán ser ciertas garantías sociales y de seguridad que inspiren confianza, autoconfianza. Mientras Sen establece la confianza

${ }^{22}$ Ibidem. 
necesaria en el sistema, Rawls es más profundo, la confianza empieza en uno mismo, en el propio proyecto vital.

$\mathrm{Al}$ autorrespeto le dedica Rawls un amplio análisis calificándolo como el bien primario más importante, a la luz de la bondad como racionalidad, y relacionándolo con la excelencia (bienes que desde todos los puntos de vista proporcionan autoconfianza) y la vergüenza moral (la ausencia de autorrespeto) (RAWLS 1979, P. 485-499).

En concreto, el autorrespeto se refiere al sentimiento que cada individuo posee de su propio valor, de que su proyecto de vida merece la pena ser llevado a cabo, y de la confianza en la propia capacidad de desarrollo. Sin el autorrespeto nada puede parecer digno de realizarse. Sin confianza en nosotros mismos carecemos de voluntad para conseguirlo. Todo deseo y toda actividad se tornan, pues, vacíos y vanos, y nos hundimos en la apatía y el cinismo. Por ello, es absolutamente necesario asegurar, desde la posición original, las bases sociales del autorrespeto, que serán "aquellos aspectos de las instituciones básicas normalmente esenciales para que los ciudadanos tengan un auténtico sentido de su valía personal y sean capaces de desarrollar y ejercer sus potestades morales y proseguir sus fines y metas con confianza en sí mismos" (RAWLS 1996, P. 345).

En cierto modo, como hemos argumentado al principio, el análisis de este bien primario podría considerarse como un fin en sí mismo y no como un medio para la justicia o la libertad. Una vida de autorrespeto es una vida de confianza, de libertad, y por tanto, de justicia. Sí sería un nivel intermedio "las bases sociales" del mismo, que ayuden a conseguir esa confianza en el propio proyecto vital, pero su consecución, consideramos que es un valor universal como fin en sí mismo y principio básico de una vida de li- 
bertad y, por tanto, elemento constitutivo del desarrollo humano. Pensamos que no se debe equiparar el autorrespeto con libertades políticas, económicas o recursos sociales, que sí son instrumentos para lograr la justicia como libertad real, pero la confianza en el propio proyecto vital es parte constitutiva y un valor universal en esta libertad.

\section{CONCLUSIÓN: DESARROLLO HUMANO}

La perspectiva de la libertad real de Amartya Sen es una propuesta de justicia social y económica de primera magnitud. Sería necesario seguir profundizando en los conceptos de nuestro autor con el objetivo de vertebrar unos fundamentos teóricos, reflexionados y pensados que articulen un desarrollo humano auténtico. Un desarrollo humano que no olvide a los seres humanos reales, de carne y hueso, muy distintos entre sí, con capacidades diferentes pero muy reales.

Necesitamos una ética universal, para un mundo globalizado. La universalidad de una perspectiva de la libertad real se debe articular y concretar en propuestas prácticas de justicia, a través de los funcionamientos y capacidades, que parten de la misma naturaleza diversa de los seres humanos. Estas capacidades nos dan las claves con las que comprender el desarrollo humano en toda su extensión.

Desde las capacidades reales, desde la propia naturaleza humana, se debe y se puede elaborar un concepto de desarrollo humano que actúe como un principio último que oriente y fundamente las políticas económicas y sociales reales de los países y de las instituciones. Un desarrollo que no tenga en cuenta sólo las necesidades de renta de los individuos, pues ello no proporciona por sí mismo una situa- 
ción de justicia, sino que tenga en cuenta la calidad de vida, el disfrute de la libertad, la realización de los propios proyectos vitales, la confianza en uno mismo y en los suyos, en definitiva, el logro de una vida digna y dichosa. Un desarrollo humano que incorpore plenamente el papel de la mujer como protagonista del desarrollo de las personas y de los pueblos. Un desarrollo humano que defina las libertades reales como principio, no sólo teórico sino también práctico (político y económico) de las principales instituciones.

Desde estas modestas propuestas pensamos que se puede construir una teoría de la justicia social y económica que desde una idea de libertad real pueda convertirse en la base teórica del desarrollo humano que debe inspirar, y de hecho lo está haciendo, la práctica política y económica de instituciones y pueblos con el fin de lograr una situación mundial de justicia donde todos los seres humanos puedan disfrutarla.

Abstract: The purpose of this paper is to show you the broad concept of "real-freedom", following both the analyses and comments of a remarkable author, Amartya Sen. This concept inspires most of the works and articles of our author. It is mainly reflected on his most important book of the past years: Development as freedom. We analyse the two points of view of the concept of "freedom" in this book. They are the constitutive role and the instrumental one. In the first role we include three concepts: Freedom as a universal value, Processes and Opportunities, and Freedom as a social commitment. In the second role we compare Sen `s instrumental-freedoms with Rawls's "primary goods" theory.

Keywords: Ethics; economy; freedom; primary goods; responsibility; rationality.

\section{REFERÊNCIAS}

\section{ARISTÓTELES. Ética a Nicómaco. Centro de Estudios Constitucionales, Madrid, 1999}


BRENNAM, G. y BUCHANAN, J. M. La razón de las normas. Economía política constitucional, Unión Editorial, Madrid, 1987

CASAS, J. "Estudio introductorio", en A. Sen, Nueva economía del bienestar, Universitat de València, Valencia, 1995

COHEN, G. "Igualdad, ide qué? Sobre el bienestar, los bienes y las capacidades" en NUSSBAUM, M. y SEN, A. La calidad de vida, FCE, Madrid, 1998

CONILL, J., El enigma del animal fantástico, Tecnos, Madrid, 1991 $\mathrm{n}^{-}$30, 1993

. "Ética del capitalismo", Claves de Razón Práctica,

. "Ideologías políticas" en 10 palabras clave en filosofía política, Verbo Divino, Navarra, 1998

- "Mercado y Justicia: un reto para la ética económica contemporánea" en Retos pendientes en ética y política, Suplemento 5 de Contrastes, Málaga, 2000

- "¿Contrato de esclavitud? Una versión del contractualismo (de Hobbes a Buchanan)", Pensamiento, vol. 57, n- 219, 2001.

DOMINGO, A. "Ética y liberalismo" en Diálogo filosófico, núm. 42, 1998.

DWORKIN, R. Los derechos en serio, Ariel, Barcelona, 1995.

. Ética privada e igualitarismo político, Paidós, Barce- 
lona, 1993.

GARGARELLA, R. Las teorías de la justicia después de Rawls, Paidós, Barcelona, 1999

HAYEK, F. The constitution of liberty, Routledge, London, 1960.

KANT, E. La metafísica de las costumbres, Tecnos, Madrid, 1999.

KYMLICKA, W. Filosofía política contemporánea.Una introducción. Ariel Ciencia Política, Ed. Ariel, Barcelona, 1995.

NUSSBAUM, M. y SEN, A, La calidad de vida, Fondo de Cultura Económica, México, 1998.

RAZ, J. The morality of freedom, Oxford University Press, Oxford, 1986.

PEDRAJAS, M. y BUENO, F. "El debate en torno a los bienes primarios en las teorías de la justicia de J. Rawls y A. Sen” en Revista agustiniana, vol. XLII, núm. 127, eneroabril 2001.

RAWLS, J. Teoría de la justicia. Fondo de Cultura Económica, 1979.

. "Las libertades básicas y su primacía" en Sobre las libertades, Paidós, Barcelona, 1990.

. El liberalismo político. Fundo de Cultura Económica, México, 1996.

SEN, A. Elección colectiva y bienestar social, Alianza, Madrid, 1976. 
SEN, A. Sobre ética y economía, Alianza, Madrid, 1987

. "Justicia, medios contra fines", Nueva economía del bienestar. Universidad de Valencia, 1995.

- Bienestar, justicia y mercado, Paidós, Barcelona, 1997.

- Freedom, Rationality and Social Choice: Arrow lectures and other essays, Clarendon Press, Oxford, 2000a .

. Development as freedom, A. Knopf, Inc, 1999. En castellano Desarrollo y libertad, Planeta, Barcelona, 2000b .

TAYLOR, Ch. Las fuentes del yo. La construcción de la identidad moderna, Paidós, Barcelona, 1996.

VAN PARIJS, P. Libertad real para todos. Qué puede justificar el capitalismo (si hay algo que pueda hacerlo), Paidós, Barcelona, 1996.

. ¿Qué es una sociedad justa? Ariel, Barcelona, 1998. 